\title{
THE COURSE OF SUBCLINICAL SYSTEMIC LYMPHEDEMA OVER A SIX-YEAR PERIOD
}

\author{
Jose Maria Pereira de Godoy, MD, PhD 1., Lívia Maria Pereira de Godoy, MD² Glauco Veloso Rodarte de \\ Melo, MD³aria de Fatima Guerreiro Godoy, OT, PhD4
}

\begin{abstract}
'Cardiology and Cardiovascular Surgery Department of the Medicine School in São José do Rio Preto (FAMERP), CNPq (National Council for Research and Development)-Brazil
\end{abstract}

\begin{abstract}
2 Physician specialized in General Practice, member of Researcher Group of the Clínica Godoy, São José do Rio Preto, SP-Brazil
3 Physician specialized in Urology Surgery, member of Researcher Group of the Clínica Godoy, São José do Rio Preto, SP-Brazil
\end{abstract}

${ }^{4}$ Occupational Therapist professor of the Post-Graduate Stricto Sensu in Medicine School in São José do Rio Preto (FAMERP) and Research Group in the Clínica Godoy, Sao Jose do Rio Preto, Brazil

\begin{abstract}
The aim of the present study was to evaluate the course of subclinical systemic lymphedema over a six-year period using bioelectrical impedance analysis. A 44-year-old woman sought our clinic six years ago with the complaint of pain and swelling in the legs upon waking that aggravated throughout the course of the day. The physical exam revealed edema in the legs and obesity, with a body mass index (BMI) of $50.6 \mathrm{~kg} / \mathrm{m}^{2}$. Bioelectrical impedance analysis was performed and revealed an increase in total intracellular and extracellular water beyond the range of normality. Over a six-year period, the patient lost 12 kilograms and her BMl was lowered, but the pattern of intracellular and extracellular water remained the same. Obesity is associated with an increase in body water characterizing subclinical systemic lymphedema, which is maintained over the years. A reduction in weight may lead to a reduction in the volume of liquids.
\end{abstract}

Key Words: Lymphedema, subclinical systemic lymphedema, bioelectrical impedance analysis 


\section{INTRODUCTION}

Obesity is worldwide public health problem that leads to a variety of physical and psychological changes. Weight loss is a challenge for these patients, many of whom seek solutions, such as bariatric surgery, but the metabolic problem often persists.

Obesity has been associated with lower limb lymphedema, which is yet another aggravating factor for this patients. ${ }^{2}$ Lymphedema is a clinical condition that leads to the buildup of macromolecules in the interstitial space, which, in turn, leads to the accumulation of liquids. In most cases, it affects the limbs and is not a generalized condition. ${ }^{3}$

Studies with animals have shown that weight gain is accompanied by changes in capillary permeability, the pumping mechanism of blood vessels and the immune defense system as well as inflammatory processes. These findings suggest a systemic change that effects the entire lymphatic system. .,5 $^{-1}$

Recent studies report a new type of edema evaluated by bioelectrical impedance analysis that leads to increases in intracellular and extracellular liquids as well as liquids in the limbs and trunk beyond the standards of normality in obese individuals. This condition of generalized edema occurs as weight
Increases and has been denominated subclinical systemic lymphedema. 6,7

The aim of the present study was to evaluate the course of subclinical systemic lymphedema over a six-year period using bioelectrical impedance analysis.

\section{Case report}

A 44-year-old woman sought our clinic six years ago with the complaint of pain and swelling in the legs upon waking that aggravated throughout the course of the day. She reported having bodily pain and a diagnosis of fibromyalgia. The physical exam revealed edema in the legs and obesity, with a body mass index (BMI) of $50.6 \mathrm{~kg} / \mathrm{m}^{2}$. Bioelectrical impedance analysis was performed and revealed an increase in total intracellular and extracellular water beyond the range of normality (Table 1).

Over a six-year period, the patient lost 12 kilograms and her BMI was lowered, but the pattern of intracellular and extracellular water remained the same. The recommendation is for continued weight loss and the practice of physical activity. 
Table 1 - Values of intracellular water (ICW), extracellular water (ECW) and total body water (TBW) over six-year period in patient compared to normal range

\begin{tabular}{|l|l|l|l|l|l|l|}
\hline & $\begin{array}{l}\text { June } \\
6, \\
2012\end{array}$ & $\begin{array}{l}\text { August } \\
2,\end{array}$ & $\begin{array}{l}\text { February } \\
15, \\
2013\end{array}$ & $\begin{array}{l}\text { May } \\
11, \\
2015\end{array}$ & $\begin{array}{l}\text { Normal } \\
\text { range }\end{array}$ & ECW/TBW \\
\hline ICW & 30.0 & 30.0 & 28.6 & 28.3 & $19.9-24.3$ & \\
\hline ECW & 19.5 & 18.9 & 18.3 & 18.4 & $12.1-14.9$ & \\
\hline ECW/TBW & 0.394 & 0.383 & 0.389 & 0.395 & $0.36-0.39$ & \\
\hline BMI & 50.6 & 49.5 & 47.6 & 46.7 & & \\
\hline Right Arm & 3.18 & 3.19 & 3.11 & 2.97 & $1.62-1.98$ & $\begin{array}{l}0.388 \\
(0.36-0.39)\end{array}$ \\
\hline Left Arm & 2.98 & 3.0 & 2.97 & 2.86 & $1.62-1.98$ & $\begin{array}{l}0.388 \\
(0.36-0.39)\end{array}$ \\
\hline Trunk & 24.0 & 24.1 & 23.7 & 22.9 & $14.7-18.0$ & $\begin{array}{l}0.3921 \\
(0.36-0.39)\end{array}$ \\
\hline Right leg & 7.78 & 7.34 & 7.11 & 7.44 & $5.13-6.27$ & $\begin{array}{l}0.400 \\
(0.36-0.39)\end{array}$ \\
\hline Left leg & 7.78 & 7.27 & 7.11 & 7.44 & $5.13-6.27$ & $\begin{array}{l}0.403 \\
(0.36-0.39)\end{array}$ \\
\hline
\end{tabular}

\section{Discussion}

The present study illustrates the sixyear course of a patient with morbid obesity (BMl: $50.6 \mathrm{~kg} / \mathrm{m}^{2}$ ) with an increase in intracellular and extracellular water as well as water in the limbs and trunk. The amount of body liquid is what most draws one's attention in this patient, demonstrating that the increase in weight does not only stem from the increase in fat tissue, but also liquids. We denominate this increase in body water beyond the range of normality subclinical systemic lymphedema. Such findings have been published by the authors and have drawn attention. However, other types of edema associated with lymphedema ${ }^{8}$ and new therapeutic options ${ }^{9}$ should be considered.
Analyzing the bioimpedance findings, a continual reduction in liquid (intracellular, extracellular, limbs and trunk) occurred with the reduction in BMI. At the last evaluation, however, increases were found in the liquid of the lower limbs and the ECW/TBW ratio, suggesting the progression to clinical lower limb lymphedema.

The increase in total body liquid in all limbs and the trunk is associated with obesity. Animal studies have shown that an increase in obesity is accompanied by changes in the pumping of the lymphatic system, capillary permeability and immune defense as well as inflammatory processes. This association has been identified in a clinical trial - as BMI increases, there is an increase in body 
liquids that can lead to generalized lymphedema, which can be determined using bioelectrical impedance analysis. This edema is seen in the lower limbs and trunk of the patient described herein.

The present study paves the path for a line of research related to obesity and lymphedema, in which we find that the reduction in obesity is associated with improvements in clinical lymphedema and the volume of body water, but not always with the normalization of body water.

\section{Conclusion}

Obesity is associated with an increase in body water characterizing subclinical systemic lymphedema, which is maintained over the years. A reduction in weight may lead to a reduction in the volume of liquids.

\section{Conflict interest}

The authors declared no have conflict interest for the study.

\section{Funding statement}

The authors declared no have funding for the study.

\section{References}

1-Rodríguez CP, González MC, AguilarSalinas CA, Nájera-Medina O. Peripheral Lymphocytes, Obesity, and Metabolic Syndrome in Young Adults: An Immunometabolism Study. Metab Syndr Relat Disord. 2018 Jun 29. doi: 10.1089/met.2018.0005. [Epub ahead of print]

2-Greene $\quad$ AK, Grant $\quad$ FD, Slavin

SA, Maclellan RA. Author information Obesity-induced lymphedema: clinical and lymphoscintigraphic features. Plast Reconstr Surg. 2015 Jun; 135(6):1715-9. doi: 10.1097/PRS.00000000000012

3-BB Lee, Antignani PL, Baroncelli TA, Boccardo, FM, Brorson $\mathrm{H}$, Campisi $\mathrm{C}$, et al., "IUA-ISVI consensus for diagnosis guideline of chronic lymphedema of the limbs," International Angiology 2015, 34(4): 311-332.

4- Nitti MD, Hespe GE, Kataru RP, Garcia Nores GD, Savetsky IL, Torrisi JS, Gardenier JC, Dannenberg AJ, Mehrara BJ. Obesity-induced lymphatic dysfunction is reversible with weight loss. J Physiol 2016; 594(23): 7073-7087.

5- García Nores GD, Cuzzone DA, Albano NJ, Hespe GE, Kataru RP, Torrisi JS, Gardenier JC, Savetsky IL, Aschen SZ, Nitti MD, Mehrara BJ. Obesity but not high-fat diet impairs lymphatic function. International Journal of Obesity 2016; (40):1582-1590. doi:10.1038/ijo.2016.96

6-Jose Maria Pereira de Godoy, Henrique Jose Pereira de Godoy, Ana Carolina Pereira de Godoy, Maria de Fatima Guerreiro Godoy. Lymphedema in patients in different BMl ranges and therapeutic response to intensive treatment. International Journal of 
Medical Science and Diagnosis Research 2018, 2(6):11-18.

7-Jose Maria Pereira de Godoy, Lívia Maria Pereira de Godoy, Rogerio Rodrigo Ramos, Ana Carolina Pereira de Godoy, Maria de Fatima Guerreiro Godoy. Subclinical systemic lymphedema caused by increased BMI in patients with lower limb Iymphedema. International Journal of Medical Science and Innovative Research 2018, 3(6):170 - 176 .

8-Pereira de Godoy JM, Pereira de Godoy HJ, Pereira de Godoy LM, Guerreiro Godoy M de F. Prevalence of Idiopathic
Cyclic Edema in Women with Lower Limb Lymphedema. Journal of Clinical Medicine. 2018;7(1):2. doi:10.3390/jcm7010002.

9-Pereira De Godoy JM, Franco Brigidio PA, Salles Cunha SX, Batigália F, De Fatima Guerreiro Godoy M. Mobilization of fluids in large volumetric reductions during intensive treatment of leg lymphedema. Int Angiol. 2013 Oct;32(5):479-82.

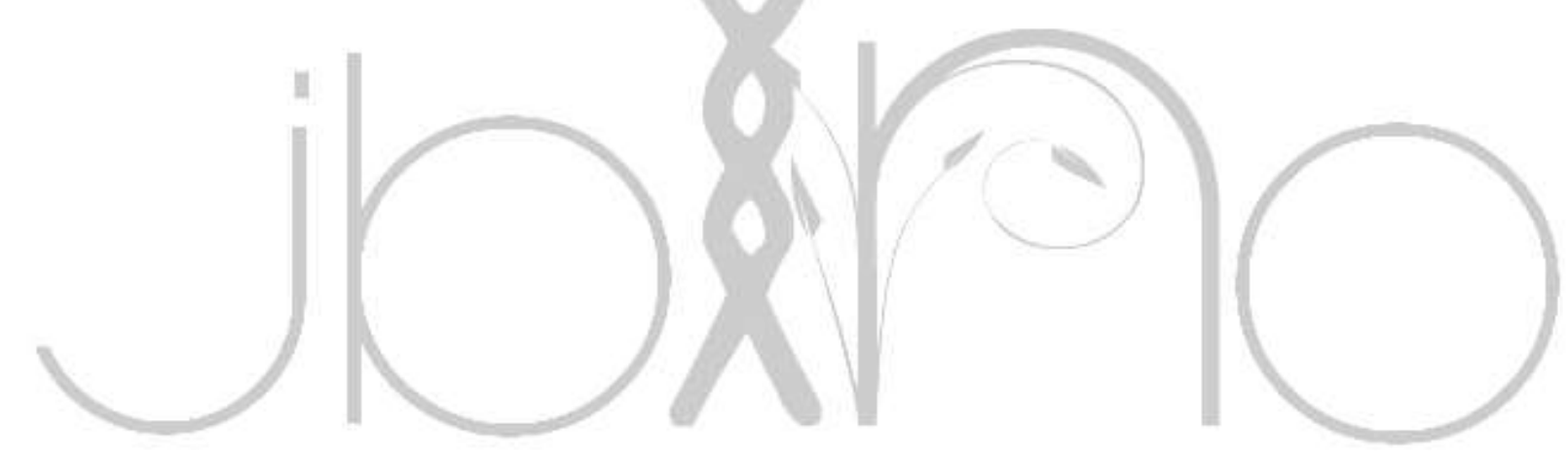

